\title{
Communication
}

\section{A novel cis-peptide bond motif inducing $\beta$-turn type VI. The synthesis of enkephalin analogues modified with 4-aminopyroglutamic acid}

Krzysztof Kaczmarek ${ }^{1}$, Maciej Kaleta ${ }^{1}$, Nga N. Chung ${ }^{2}$, Peter W. Schiller ${ }^{2}$ and Janusz Zabrocki ${ }^{1} \bowtie$

${ }^{1}$ Institute of Organic Chemistry, Technical University of Łódż, 90-924 Łódź, Poland,

${ }^{2}$ Laboratory of Chemical Biology, Clinical Research Institute of Montreal, Montreal, Quebec, Canada

Received: 9 October, 2001; accepted: 12 November, 2001

Key words: 4-aminopyroglutamic acid, cis-peptide bond, $\beta$-turn mimetic, constrained enkephalin analogues

\begin{abstract}
A new pathway leading to a mixture of four isomers of 4-aminopyroglutamic acid is described. Michael type addition of $\mathrm{Z}-\Delta \mathrm{Ala}-\mathrm{OMe}$ to enolates prepared from acylaminomalonates, followed by hydrolysis and decarboxylation give protected 4-aminopyroglutamic acid with the cis:trans ratio approximately $3: 2$. This mixture was incorporated into Leu-enkephalin (position 2-3). After separation of peptides it appeared that all analogues were essentially inactive in guinea pig ileum and mouse vas deferens bioassays.
\end{abstract}

The interest in understanding the role of cis-amide bond for peptide bioactivity has led to the syntheses of several compounds with the peptide bond locked in cis-geometry.
Burney et al. [1] designed a mimetic of cis-peptide bond based on an extension at $\mathrm{C}^{\gamma}$ (or 4-) of pyroglutamic acid residue 1 (Fig. 1). Their computer modeling data suggest that, depend-

\footnotetext{
${ }^{\star}$ Presented at the XVI Polish Peptide Symposium, September 1-4, 2001, Jagiellonian University, Kraków, Poland.

${ }^{\star}$ This work was supported by the State Committee for Scientific Research (KBN, Poland) and by the Heart and Stroke Foundation of Quebec (Canada).

${ }^{凶}$ Corresponding author: phone: (48 42) 636 6588; fax (48 42) 636 5530; e-mail: zabrocki@ck-sg.p.lodz.pl Abbreviations: Ac, acetyl; APy, $(2 S, 4 S)-4$-aminopyroglutamic acid; apy, $(2 R, 4 R)-4$-aminopyroglutamic acid; aPy, (2S,4R)-4-aminopyroglutamic acid; Apy, (2R,4S)-4-aminopyroglutamic acid; Boc, tert-butyloxycarbonyl; GPI, guinea pig ileum; MBHA, $p$-methylbenzhydrylamine resin; MVD, mouse vas deferens; TFA, trifluoroacetic acid; Z, benzyloxycarbonyl.
} 
ing on the stereochemistry on both chiral centers, these should stand for VIa and VIb $\beta$-turn mimetics. The incorporation of cyclic structure elements into short flexible peptides diminishes the number of existing conformers, facilitating conformational analysis. On the

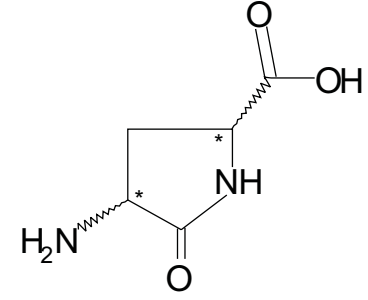

1

(2S, 4R), (2R,4S) - trans $(2 S, 4 S),(2 R, 4 R)$ - cis the presence of diisopropylethylamine. The peptide resin was cleaved by treatment with anhydrous $\mathrm{HF}$ /anisole (9:1 ratio, $\left.0^{\circ} \mathrm{C}, 1 \mathrm{~h}\right)$. Lyophilization of water extracts obtained after routine work-up gave crude product as a mixture of four peptides with $82 \%$ total yield.<smiles>[Y]N[C@@]1(C(=O)OCC)C(=O)N[C@@H](C(=O)OCC)[C@H]1C</smiles>

$\underline{2}$

$X=A c$, Boc, $Z$

\section{Figure 1}

other hand, introduction of such motifs into bioactive peptides can be used to explore the importance of $\beta$-turn and side-chain geometry for their selectivity and potency. We have previously presented unequivocal synthesis of trans-1 $((2 S, 4 R)$-aPy) [2]. Unfortunately, the $(S, S)$ and $(R, R)$ isomers cis-1 are only minor products of our procedure and we were forced to develop an alternative route to either exclu-

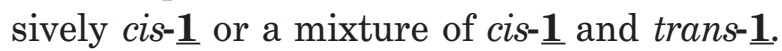

\section{MATERIALS AND METHODS}

Chemistry. All reagents and solvents were ACS grade or better and were used without further purification. MBHA resin was purchased from Novabiochem (Switzerland). The typical protocol of solid phase peptide synthesis (SPPS) was applied with the Boc/Bzl strategy, O-(7-azabenzotriazol-1-yl)-1,1,3,3-tetramethyluronium hexafluorophosphate (HATU, Perceptive Biosystems) as the coupling agent and a $50 \%$ solution of trifluoroacetic acid in dichloromethane for deprotection of Boc- $\mathrm{N}^{\alpha}$-terminal amino group. Capping of nonacylated $\mathrm{N}^{\alpha}$-terminal amino groups in growing peptide chain was achieved with acetic anhydride in
All four enkefalin analogues were separated and purified by preparative HPLC (LDC Analytical) on reversed-phase support (Vydac $\mathrm{C}_{18}$ $10 \mu \mathrm{m}$ column, $250 \times 22 \mathrm{~mm}$ ) with isocratic mobile phase $20 \%$ of B in A (B: $0.038 \%$ TFA in $82 \%$ acetonitrile/water, A: $0.05 \%$ TFA in water), flow $20 \mathrm{ml} / \mathrm{min}$ and detection at $\lambda=214$ $\mathrm{nm}$. Their homogeneity was checked with analytical HPLC (ThermoSeparation system equipped with AS3000 autosampler, P4000 pump and scanning SpectraFocus detector, Vydac $\mathrm{C}_{18} 5 \mu \mathrm{m}$ column, $250 \times 4.6 \mathrm{~mm}$, isocratic elution $20 \% \mathrm{~B}$ in $\mathrm{A}$, flow $1 \mathrm{ml} / \mathrm{min}$ ) and was found to be higher then $98.5 \%$ for each analogue. The structures of the pure peptides were confirmed by FAB mass spectra which were recorded on an APO Electron (Ukraine) Model MI 1200 1E mass spectrometer equipped with a FAB ion source (found $\mathrm{MH}^{+}=567.4, \mathrm{MNa}^{+}=589.4$, calculated $\mathrm{M}=$ 566.66 for $\mathrm{C}_{29} \mathrm{H}_{38} \mathrm{~N}_{6} \mathrm{O}_{6}$ ).

Biology. For the determination of their in vitro opioid activities, the three of the four Leu-enkefalin analogues synthesized (the analogue containing $(2 S, 4 R)$-aPy residue was described earlier [2]) were tested in the bioassays based on the inhibition of electrically evoked contractions of guinea pig ileum 
(GPI) and mouse vas deferens (MVD). The GPI assay is usually considered as being representative for $\mu$ opioid receptor interactions, even though the ileum does also contain $\kappa$ opioid receptors. In the MVD assay opioid effects are primarily mediated by $\delta$ opioid receptors, but $\kappa$ and $\mu$ receptors also exist in this tissue. The GPI and MVD bioassays were carried out as reported in details elsewhere [3, 4].

\section{RESULTS AND DISCUSSION}

\section{Chemistry}

We decided to focus our attention on a method that could conveniently deliver a mixture of all four stereoisomers of our motif. Michael type addition of in situ generated $\mathrm{Z}-\Delta \mathrm{Ala}-\mathrm{OMe}$ to enolates prepared from diethyl acylaminomalonates $(\mathrm{X}=\mathrm{Ac}, \mathrm{Boc}, \mathrm{Z})$ gave linear adducts which underwent spontaneous cyclisation to N-protected compounds 2 (Fig. 1, Scheme 1). In all three products $\underline{\mathbf{2}}$ the
${ }^{1}$ H-NMR spectra. Crude mixture 2 (X=Boc, Scheme 2) was separated by flash chromatography into cis-2 and trans- $\mathbf{2}$ racemates. Because of the small difference in the rate of basic hydrolysis between both ester functions we were unable to selectively split the malonate ethyl group in either the cis or trans isomer. Extensive basic hydrolysis followed by decarboxylation in boiling dioxane delivered mixtures of cis and trans N-protected motifs, independent of the geometry of the starting bis-acid (cis or trans). In the case of Boc-1 the cis:trans ratio was approximately $3: 2$ starting from the cis and about 2:3 starting from the trans isomer. The obtained Boc-motif with the cis:trans ratio about $3: 2$, being a mixture of all four stereoisomers, was incorporated into positions $2-3$ of Leu-enkephalin amide, giving crude product containing four diastereoisomeric peptides. HPLC profile showed (Table 1) that they were chromatographically separable. Their ratio in the crude mixture was about $2: 3: 2: 3$ (in the order of retention times), similar to the compo-<smiles>[X]NC(CO[Na])C(OC)O[Na]</smiles>

$X=A c$, Boc,$Z$<smiles>[Y4]=N[C@@]1(COCC)C[C@H](C(=O)OCC)NC1=O</smiles>

2: 4 stereoisomers

\section{Scheme 1}

$\mathrm{N}$-protecting group was found to be the same as in the starting aminomalonate derivative, which was confirmed by FAB-MS and sition of the starting Boc-motif. Due to suspected differences in coupling rates of Boc-motif stereoisomers, we used only 1.1

Table 1. Analytical data of enkephalin analogues

\begin{tabular}{|c|c|c|c|c|}
\hline \multirow[t]{2}{*}{ Compound } & \multicolumn{2}{|c|}{ HPLC } & \multicolumn{2}{|c|}{ FAB-MS } \\
\hline & $\mathrm{t}_{\mathrm{R}}(\min )$ & area $(\%)$ & calc. & found $\left(\mathrm{MH}^{+}\right)$ \\
\hline H-Tyr-(2S, $4 R)$-aPy-Phe-Leu-NH ${ }_{2}[2]$ & 10.14 & 18.3 & 566.66 & 567.4 \\
\hline H-Tyr-(2S, $4 S)$-APy-Phe-Leu-NH 2 & 10.76 & 25.3 & 566.66 & 567.4 \\
\hline H-Tyr-(2R,4S)-Apy-Phe-Leu-NH ${ }_{2}$ & 11.77 & 17.3 & 566.66 & 567.4 \\
\hline H-Tyr-(2R,4R)-apy-Phe-Leu-NH ${ }_{2}$ & 14.69 & 26.3 & 566.66 & 567.4 \\
\hline
\end{tabular}



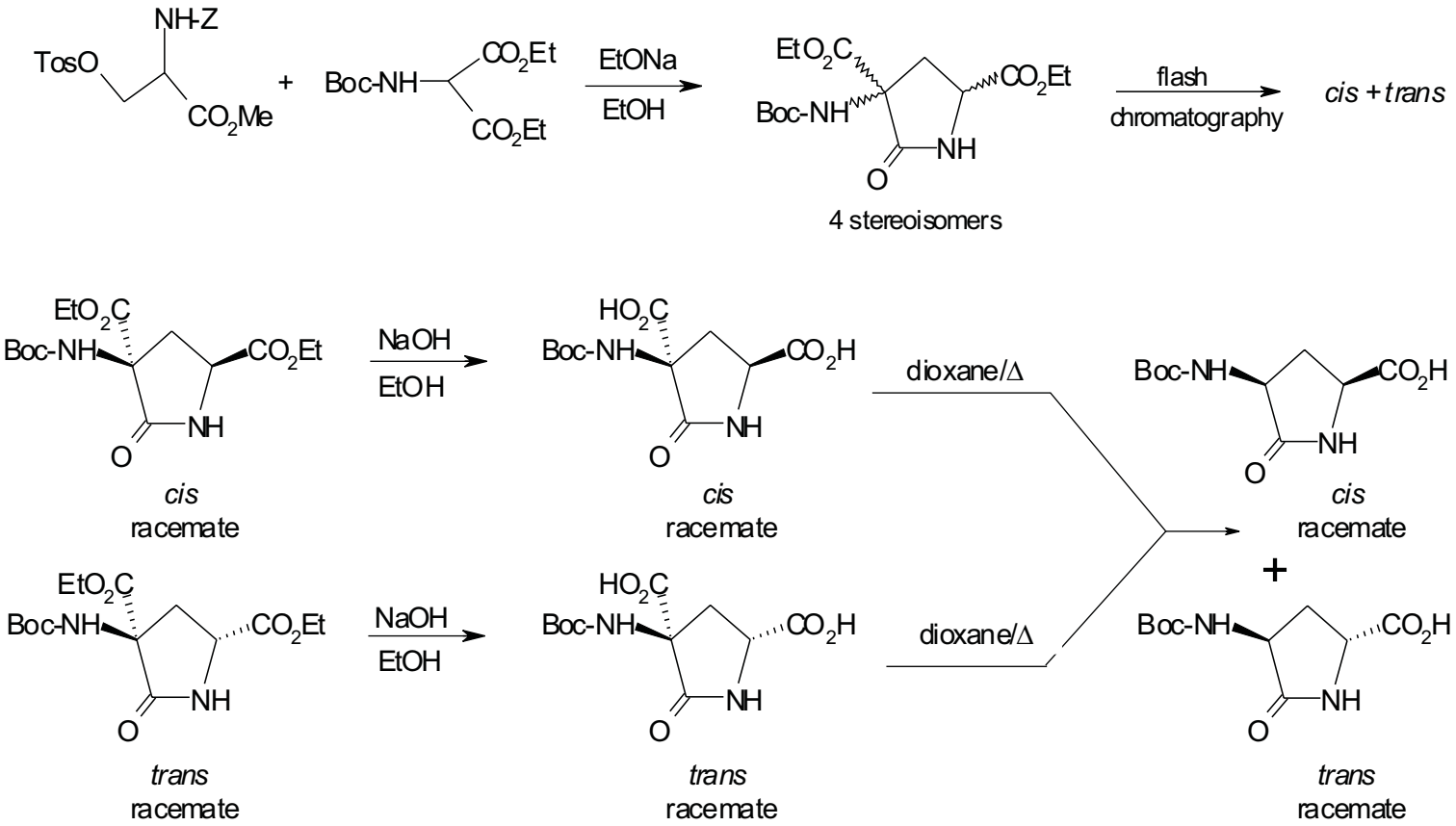

\section{Scheme 2}

equivalents of this derivative in SPPS in order to avoid changes in the composition of the final peptides mixture. This helped us to assign structures of both analogues containing trans-motif residue, as racemic Boc-trans-motif was a minor compound in the substrate taken for solid phase synthesis. Moreover, direct assignment of the chirality of trans-motif residues in both peptides was possible by coinjection with the original sample of an analogue containing $(2 S, 4 R)$-aPy residue, whose synthesis was described earlier [2]. In order to an analogue containing $(S, S)$-APy residue incorporated as a Fmoc-derivative. This last substrate was available as a side product obtained during previously described work [2].

\section{Biology}

The results are displayed in Table 2 . As in the case of the already described [ $2 S, 4 R)$ $\mathrm{aPy}^{2-3}, \mathrm{Leu}^{5}$ ]-NH 2 enkefalin [2], the three remaining analogues were essentially inactive. All three peptides did show weak agonist ac-

Table 2. Guinea pig ileum (GPI) and mouse vas deferens (MVD) assay of opioid peptide analogues

\begin{tabular}{|c|c|c|}
\hline Compound & $\begin{array}{c}\text { GPI } \\
\mathrm{IC}_{50}[\mathrm{nM}]\end{array}$ & $\begin{array}{c}\text { MVD } \\
\mathrm{IC}_{50}[\mathrm{nM}]\end{array}$ \\
\hline H-Tyr- $(2 S, 4 R)-$ aPy-Phe-Leu-NH $2[2]$ & $>10000$ & $>10000$ \\
\hline H-Tyr- $(2 S, 4 S)$-APy-Phe-Leu- $\mathrm{NH}_{2}$ & 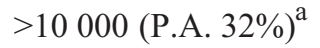 & 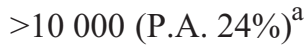 \\
\hline H-Tyr- $(2 R, 4 S)$-Apy-Phe-Leu-NH 2 & $>10000$ inactive & $>10000$ (P.A. 38\%) $^{\mathrm{a}}$ \\
\hline H-Tyr- $(2 R, 4 R)$-apy-Phe-Leu- $\mathrm{NH}_{2}$ & $>10000$ inactive & 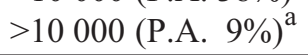 \\
\hline
\end{tabular}

${ }^{\mathrm{a}}$ P.A. = partial agonist (value in parentheses indicates maximal inhibition of the contractions (\%) obtained at a concentration of $10 \mu \mathrm{M}$ )

assign chirality in analogues containing cis-motif residues, we performed solid phase peptide synthesis (on a 0.02 mmole scale) of tivity at a very high concentration $(10 \mu \mathrm{M})$ in the MVD assay, but in the GPI assay only the analogue containing $(S, S)$-APy residue was a 
weak agonist. This is a clear evidence that $\beta$-turn type VI should be excluded from the list of suggested enkephalin conformations which are able to bind to both $\mu$ and $\delta$ receptors.

\section{R E F E R E N C E S}

1. Paul, P.K.C., Burney, P.A., Campbell, M.M. \& Osguthorpe, D.J. (1992) Bioorg. Med. Chem. Lett. 2, 141-144.
2. Kaczmarek, K., Zabrocki, J., Łachwa, M. \& Lipkowski, A. (1999) in Peptides 1998 (Proc. 25th Eur. Peptide Symposium), (Bajusz, S. \& Hudecz, F., eds.) pp. 668-669, Akademiai Kiado, Budapest.

3. Schiller, P.W., Lipton, A., Horrobin, D.F. \& Bodanszky, M. (1978) Biochem. Biophys. Res. Commun. 85, 1322-1338.

4. DiMaio, J., Nguyen, T.M.-D., Lemieux, C. \& Schiller, P.W. (1982) J. Med. Chem. 25, 14321438. 